\title{
Middle school student attitudes toward science, and their relationships with instructional practices: a survey of Chinese students' preferred versus actual instruction
}

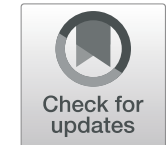

\author{
Gavin W. Fulmer ${ }^{1 *}$ (D) Hongjia Ma ${ }^{2}$ and Ling L. Liang ${ }^{3}$
}

\footnotetext{
* Correspondence: gavin-fulmer@ uiowa.edu

${ }^{1}$ University of lowa, N289 Lindquist Center, lowa City, IA 52242, USA Full list of author information is available at the end of the article
}

\begin{abstract}
This study explored relationships between students' attitudes toward science and their preferred versus actual experience of cooperative, constructivist-oriented, or direct instruction. The sample consisted of 1334 Chinese middle school students in physics and chemistry classrooms. Results showed that students report experiencing more direct instruction, very little constructivist-oriented instruction, and a moderate amount of cooperative instruction. Attitudes toward science were positively related to cooperative teaching strategies like group work in class or developing small-group projects. There was no significant effect of constructivist-oriented instruction or of direct instruction on students' attitudes. Whereas previous studies demonstrated positive impacts of constructivist teaching on student understanding of science concepts, student attitude toward school science appears to be more related to social interaction or cooperation. Lack of any statistically significant differential effect from constructivist-oriented instruction might also be related to the overall low incidence of such instruction experienced by our sample.
\end{abstract}

Keywords: Attitudes toward school science, Science teaching, Secondary science, Student surveys

Building and sustaining students' attitudes toward science has been a consistent goal in science education and a topic of significant research, as attitudes are an important aspect of students' persistence in school science and interest in pursuing science careers (Osborne, Simon, \& Collins, 2003; Tytler \& Osborne, 2012). Unfortunately, students' attitudes toward science generally decline over the middle and high school years (George, 2000; Potvin \& Hasni, 2014). Therefore, finding ways to support middleschool students' attitudes toward science can help contribute to efforts to teach and retain students in school science.

Previous studies have demonstrated the potential for constructivist- and inquiryoriented teaching to increase students' attitudes toward science (Juuti, Lavonen, Uitto, Byman, \& Meisalo, 2010; Osborne et al., 2003), but the majority of such work has been conducted in Western settings. While informative and influential, we also see a need to study the phenomenon in East Asian settings because of the different classroom context, norms, and expectations there. We therefore contribute to the literature by

(c) The Author(s). 2019 Open Access This article is distributed under the terms of the Creative Commons Attribution 4.0 International License (http://creativecommons.org/licenses/by/4.0/), which permits unrestricted use, distribution, and reproduction in any medium, provided you give appropriate credit to the original author(s) and the source, provide a link to the Creative Commons license, and indicate if changes were made. 
examining the effects of forms of instruction on science attitudes in East Asian settings (Osborne et al., 2003: 1072). Furthermore, whereas increases in attitude toward science are well demonstrated when treated as an explicit goal of a curriculum or program (see also Koballa \& Glynn, 2007, p. 85, for their brief review on interventions) or that look at the benefits of out of school experiences (Gibson \& Chase, 2002; Maltese \& Tai, 2010), in this study we examine the effects of different forms of instruction on students' attitude toward science even when attitude was not an explicitly-stated outcome for the lessons. We address these areas through a survey of middle-school students' attitudes towards science and its relationship to their reports of actual instruction and their preferred instruction.

This study is based in the Chinese education context where previous research indicates that teacher-centered, direct instruction is rather more prevalent even as inquiryoriented approaches have been encouraged (Huang, Ding, \& Hu, 2016). The reasons for this are multifaceted. The Chinese Ministry of Education (MOE) released revised guidelines for various subjects (e.g., Ministry of Education (MOE), 2011) that encouraged more student-centered teaching approaches, yet the translation of these into classroom practices is also filtered through teachers' own experiences and the goals and expectations for national examinations (Liang, 2017). Gao and Watkins (2002) showed that Chinese secondary science teachers' views of teaching fall into two categories: molding and cultivation. The molding orientation relates particularly well to teachercentered activities such as knowledge delivery and exam preparation, whereas the cultivation orientation addresses activities such as ability development, promoting attitudes, and guiding conduct. Gao and Watkins also found that teachers overwhelmingly viewed the benchmark for success to be external examination performance, regardless of whether they endorsed the molding or cultivation view. This finding is corroborated by Yip's (2001) work in Hong Kong, showing how pre-service teachers predominantly view students as "empty vessels to be filled with knowledge from the authority" (p. 758), and that many of these views persisted despite participation in a teaching methods course that emphasized constructivist-oriented science teaching approaches. These findings are consistent with the heavy emphasis on examinations and a focus on performativity in Chinese education (Tan, 2012), which is itself part of a broader trend throughout East Asian societies (Kennedy, 2007). Given this status, we anticipated that direct instruction in the science class may be more prevalent in our study, while using instruments that allow for gathering data on varied forms of teaching. The study therefore bridges ongoing work on the role of instruction on students' attitudes towards science in Western settings (e.g., Juuti et al., 2010) with work on Chinese students' attitudes towards science (Du \& Gao; Wu \& Gao), by focusing on the roles of the forms of instruction that students experience.

\section{Background and related literature}

\section{Attitudes toward science}

Attitudes toward science are the positive or negative opinions that individuals have about science, based on their perceptions of science-as a school subject, as an aspect of society, and as a human endeavor (Osborne et al., 2003). Attitude is a relatively more dispositional construct that changes slowly and influences the broad range of 
perceptions, views, and values regarding science, as well as their interest in pursuing potential careers in science. According to the expectancy-value theory (Eccles \& Wigfield, 2002; Wigfield \& Eccles, 2000), a student's attitude toward school science can be explained by two main factors: the student's expectations of success, and the value that the student places on success. These include belief about the student's own ability for school science, expectation for success in school science, and usefulness and importance of school science. The expectancy-value theory provides a psychological basis for the study of both persistent attitudes toward school science and of transient, situational motivations. Furthermore, the expectancy-value theory aligns with the Relevance of Science Education (ROSE; Schreiner \& Sjøberg, 2004) project questionnaires on student attitudes toward school science: ability views, expectation of success, career values, and social values (see Schreiner \& Sjøberg, 2004, for more detail on the item development). The ROSE project has informed several international comparisons on students' views about and attitudes toward school science.

Attitude toward school science is not only a by-product of teaching but can be an important outcome in its own right (Osborne et al., 2003). Attitudes toward science can also have statistically significant relationships with student achievement and gains in content knowledge (Bybee \& McCrae, 2011; Newell, Zientek, Tharp, Vogt, \& Moreno, 2015), which may be a direct effect or be indirect through the influence of attitude on students' engagement, motivation, or persistence with academic study of science. Therefore, attitude has been identified as an important measure for assessing science teaching, because it is related to students' performance in science and their retention in science majors. For example, attitudes toward science were shown to have positive relationships with course performance (Hazari, Tai, \& Sadler, 2007) and science coursetaking patterns (Singh, Chang, \& Dika, 2005). The possible mechanism for such effects is that attitudes can provide indirect support by increasing students' willingness to spend time on and persist in learning science (Singh, Granville, \& Dika, 2002) or have a stronger sense of the value of direct effort (Newell et al., 2015), thus yielding higher achievement and course persistence.

Attitudes literature reveals complex relationships among attitude with student demographics, class experiences, and behaviors. Gender, economic, and racial differences have received much attention over the years, revealing that students have more positive attitudes toward science when they believe it is welcoming of women and minorities (Fulmer, 2014), or provides a greater sense of fit with their own values or identities (Aschbacher, Li, \& Roth, 2010; Weinburgh, 1995), or into a 'science culture' (Taconis \& Kessels, 2009). Rice, Barth, Guadagno, Smith, and McCallum (2013) explored the differences in role of social support for attitude toward science and math, finding that gender played a role in the types of social support-finding that females drew on parent and teacher support whereas males drew more on peer support. These findings may also be influenced by the prevailing culture. Gender differences in attitudes, for example, may be more prominent in Western samples (Fulmer, 2014; Sadler, Sonnert, Hazari, \& Tai, 2012; Weinburgh, 1995), but in Asian settings may be missing (Peer \& Fraser, 2015; Wang \& Berlin, 2010) or reversed (Hong \& Lin, 2011). But in a few recent studies conducted in the Chinese context, male middle school students' attitudes toward science were consistently reported to be more positive compared to their female counterparts' (Du \& Gao, 2010; Wu \& Guo, 2019). This led Potvin and Hasni (2014) to conclude in 
their review that there are no clear patterns on gender gaps in attitude internationally. We choose to include a gender analysis in our study to help us better understand the possible differences in relationship between students' attitudes and instructional modes.

Prior research has explored the ways that attitudes toward science are linked to students' learning experiences and the school context. Raved and Assaraf (2011) found that students had more positive attitudes when they felt a connection with the teacher and the relevance of the topic. Basl's (2011) analysis of PISA 2006 data showed that school preparation was consistently more important for students' developing awareness of science careers than family background. Maltese and Tai (2010) interviewed practicing scientists and graduate students and found that school-based activities were particularly important for girls to develop interest in science. Vedder-Weiss and Fortus (2012) noted that Israeli democratic schools, which emphasize autonomy and selfdirection, do not have such attitude declines. Attitudes, interest, and motivation have also been found to have important peer and social support effects (Rice et al., 2013; Vedder-Weiss \& Fortus, 2012), making it clear that understanding the school's academic context is important. Thus, in this study we considered schools of different types, so we could consider possible academic context effects.

Despite the body of knowledge reviewed above, we know relatively little about how attitudes can be influenced by how students are taught science in school. Studies in this area suggest that students prefer learning experiences involving activity-based practical work, discussion, investigations, and the stressing of the relevance of science through issue-based instruction (Juuti et al., 2010; Koballa \& Glynn, 2007). Recent work has explored this effect, but with some mixed findings. Traditional teacher-centered instruction is associated with lower attitudes toward science (Potvin \& Hasni, 2014). By contrast with traditional teaching, studies on reformed teaching show better promise. Houseal, Abd-el-Khalick, and Destefano (2014) found increases in students' perceptions of scientists after a partnership program with visiting scientists. Koksal and Berberoglu (2014) found a significant but small effect $\left(\eta^{2}<10\right)$ of a guided inquiry approach on students' attitudes toward science. Zeyer (2017) found that students with better systems-thinking had higher attitudes toward science. On the other hand, Kanter and Konstantopoulos (2010) found a decline in minority students' attitudes toward science after a project-based science curriculum. So, while there is some overall pattern there is still substantial room to examine the role of teaching strategies on students' attitudes. Furthermore, we do not yet know if these preferences or experiences of instruction are particular to specific acts of teaching (e.g., doing a laboratory), or if they are part of an overall pattern in forms of teaching such as direct instruction, constructivist-oriented instruction, etc. Teacher education and professional development do not usually focus solely on one behavior like doing laboratories, but on a set of related pedagogical strategies in which students may, for example, interact with objects, plan studies of their own, and carry out laboratory work (Hand, Cavagnetto, Chen, \& Park, 2016; Minstrell \& Kraus, 2005). As Potvin and Hasni (2014) found, the overall positive effects of collaborative work and of inquiry-oriented teaching are confounded by the varied definitions and operationalizations of the inquiry teaching approaches, such as bringing in professional scientists or doing extensive group work. So, for this study we sought to distinguish among different instructional practices to make a clearer comparison among forms of instruction and the effects on students' attitudes. 
Drawing on the expectancy-value theory, we posit that there are connections between the instructional practices that students experience in class and their developing attitudes toward school science (Wang \& Degol, 2013). We argue that constructivistoriented teaching can yield better attitudes in two ways. First, as students take ownership of the knowledge building process in class, they gain epistemic authority and thus increase their sense of ability and outcomes expectation (Durik, Shechter, Noh, Rozek, \& Harackiewicz, 2015). Second, as students use social interactions to develop knowledge together, they increase their sense of social support and social interaction in school science, which would lead to greater sense of personal value (Urdan \& Schoenfelder, 2006; Wang \& Eccles, 2012).

To examine these relationships, we build on existing work that uses student responses on their experienced and preferred instruction. Examining students' experiences of instruction can provide valuable information not only about the forms of instruction that they experienced (Fulmer \& Liang, 2013; Marsh, 1984), but also how this can relate to student outcomes. Our attention to both actual and preferred instruction reflects the fact that meeting students' expectations could increase their satisfaction and situational interest, and therefore could contribute to the development of positive attitudes toward science (Juuti et al., 2010). So, we examine not only the level of experienced instruction, but how this may differ from what students prefer. Drawing on such information to support teachers in using students' preferred instructional strategies may enhance students' positive feelings in the class and, thus, support the development of their attitudes toward science.

In addition, most previous studies on the relationship between forms of instruction and student attitudes were conducted in Western countries. As a field, we do not know if the relationship between forms of instruction and students' attitude is consistent across national and cultural boundaries. Are there common aspects of the school experience that may lead to improved attitudes toward science for both Western and Asian students? Exploring questions such as this provide insight not only within each context but also about the relevance and translation of educational concepts across contexts. Indeed, this relevance goes both directions: as accountability systems using high-stakes examinations are becoming more common in Western countries, the lessons learned from examination-driven education systems of East Asia may prove informative for educators throughout the globe.

In this study, we addressed these gaps in extant literature through a survey of middle-school students' preferences and experiences of direct, constructivist-oriented, or cooperative teaching, and how this relates to their attitudes toward science. We posed three research questions. Questions 1 and 2 address the actual and preferred instruction and whether this is affected by gender or school type. Question 3 addresses the influence on attitudes of forms of instruction.

\section{Forms of science instruction}

This study examines some of the forms of instruction that science teachers may use in class, which derive from different theories about learning and teaching. For this study, we identify three broadly defined forms of science instruction: direct, constructivistoriented, and cooperative. 
Direct instruction is instruction in which the teacher presents content to students and is underscored by the focus of attention on the teacher and communication from the teacher to students (Cobern et al., 2010; Juuti et al., 2010). Our usage of the term direct instruction is distinct from the very specific definitions such as Explicit Direct Instruction (Hollingsworth \& Ybarra, 2017). Rather, we use it in the broader sense of teacher-led instruction organized so that concepts and skills are built up over time, in an order specified by the teacher, characterized by the teacher telling, modeling, and representing accurate content to students (Clark, Kirschner, \& Sweller, 2012; Kame'enui, Jitendra, \& Darch, 1995; Kirschner, Sweller, \& Clark, 2006). The general format of direct instruction is also sometimes called teacher-centered instruction, and in the US often referred to as "didactic" approaches. This is also consistent with widespread patterns of instruction that are found in Chinese contexts (Huang et al., 2016). It is recognizable when teachers retain the epistemic authority of the class and, in the more extreme examples of this approach, when students remain silent and attentive to the teachers' actions and statements. In such circumstances, student activities may include working individually on an assigned problem or observing the teacher delivering new content in a lecture format (Juuti et al., 2010).

In contrast to direct instruction, there has been increasing attention to alternatives that emphasize students taking more epistemic authority for developing conceptual understanding or for more social interaction in class among students. Two broad categories representing these forms are Constructivist-oriented and Cooperative. According to the review by Baviskar, Hartle, and Whitney (2009), constructivist-oriented teaching typically involves some combination of four elements: eliciting students' knowledge, creating cognitive dissonance in some way, applying knowledge with feedback, and reflection on learning. These are also often denoted as inquiry-oriented teaching (Furtak, Seidel, Iverson, \& Briggs, 2012; Loyens \& Rikers, 2016). Student activities during constructivist-oriented teaching may include the students developing concept maps about their ideas, or discussing concepts as a class (Juuti et al., 2010).

Cooperative instruction is characterized by students interacting with each other in pairs, groups, or teams (Slavin, 2016), informed by theoretical perspectives from social constructivism as applied to science teaching and learning (Driver, Asoko, Leach, Mortimer, \& Scott, 1994). As Gillies (2003) noted, simply putting students into groups is insufficient to support their learning-the students must understand the ways in which their cooperation supports not only group success but individual success. A variety of approaches to cooperative grouping have been proposed, such as jigsaw, home-group, etc. (Hänze \& Berger, 2007). Student activities during such times include working in pairs or teams, or using a specific form of grouping such as the jigsaw (Juuti et al., 2010). As mentioned above, the Cooperative and Constructivist-oriented categories should not be considered mutually exclusive, as combinations are certainly possible both in practice (Loyens \& Rikers, 2016; Slavin, 2016).

Much science education research work has demonstrated the benefits of constructivist-oriented and cooperative approaches compared to direct instruction (Koksal, 2014; Liang, Fulmer, Majerich, Clevenstine, \& Howanski, 2012). However, there has been debate in the field as some scholars argued for the superiority of direct instruction (Kirschner et al., 2006). Yet, critiques of this type are often themselves criticized for using a strawman argument of a purely unguided "discovery" approach that is, 
in practice, relatively uncommon in science education (Dean \& Kuhn, 2007). Rather, well-controlled experimental studies of direct and constructivist-oriented teaching show either comparable results under fair comparisons (Cobern et al., 2010) or that there is a long-term benefit of constructivist approaches (Dean \& Kuhn, 2007).

\section{Research questions}

1. What forms of science instruction do students experience in class, and does this differ from their preference for instruction?

2. Are there differences in student perceptions of actual and preferred instruction by gender or by type of school?

3. How is attitude toward science explained by the discrepancy between students' preference for and actual experience of instruction, after accounting for gender and type of school?

\section{Methods}

\section{Setting and samples}

The study focused on instructional practices in physics and chemistry classes from student perspectives. Our data were collected in 16 randomly-selected junior high schools in a well-developed city in Jiangsu province of China. The schools were of three types according to level of academic prestige- $\mathrm{A}, \mathrm{B}$, and $\mathrm{C}$-where A schools were highest in academic standing and $\mathrm{C}$ schools were lowest in academic standing. These three types are well representative of the schools in this city. Our prior experience in these schools suggests that it is a mostly teacher-centered classroom environment, with an average of about $70 \%$ of class time devoted to teacher lectures and about $30 \%$ of time on student questions, discussion, and laboratory experiments. To our knowledge there is no systematic difference among the schools by type on the teaching strategies or approaches, but because of academic standing there would be differences in the level of difficulty of the science content. Also, students in the type A schools are more likely to behave attentively and interactively in class, whereas students in type $\mathrm{C}$ schools may be more likely to be inattentive or to require teachers' active management for classroom discipline.

The initial sample comprised 1334 Grade- 9 students (50.9\% male). Grade-9 students in these schools take a set course including both physics and chemistry for the entire year. Of these 1334 students, full response data was available for 1299 students (50.2\% male). The survey process was approved for ethics clearance by the institution and vetted by school principals. The students completed the questionnaire in class under direction of their teachers, who advised them that the survey was for research purposes only and would not affect their grades or standing. All questionnaires were anonymous to protect students' confidentiality.

\section{Instrument}

We implemented one survey instrument with two sections of items-students' attitudes toward science, and their experiences of instruction-adapted from a previously validated survey study by Juuti et al. (2010). The attitude questions adopted by Juuti et al. 
(2010) are themselves based on the questionnaires used by the ROSE study (Schreiner \& Sjoberg, 2004; Sjøberg \& Schreiner, 2010), in which scholars around the world worked to establish validity through expert review, piloting, student interviews, etc. More detail on the questionnaire development process and the project goals regarding validity are summarized in Sjøberg's and Schreiner's (2004) report. Reliability information for the present sample is presented below when discussing our factor analyses. The items were translated into Chinese, with some items were modified slightly for the mainland Chinese context. To perform the translation, one author and one graduate student each independently translated the questionnaire into Chinese, then compared their translations. No substantial differences were found, so the final version was based on merging the two translations.

Two sections were analyzed for this report: students' attitudes toward science, and students' reports of instruction as they actually experienced it or that they would prefer. The first section of the questionnaire addressed students' attitude toward school science, comprising 8 items about their perceptions and attitudes about school science, each on a 4-point Likert-type scale (see Table 1). The items address varying aspects of attitude towards science (here, physics and chemistry were stated explicitly rather than putting the general term, "science") and technology. The various items are consistent with expectancy-value theory because they include not only interest in the immediate course content and stimulated curiosity, but also importance for society, and helpfulness for future careers in science and technology. Because of the course structure for the Grade-9 students in the sample, we have information on their preference for instruction, actual experience of instruction, and attitude toward science overall but cannot disaggregate by subject area (e.g., actual instruction in chemistry or in physics).

The second section of the questionnaire addresses teachers' instruction. It contains 23 items, each answered on two scales: (1) a 5-point scale about the actual frequency that certain teaching methods occurred in classroom, and (2) a 5-point scale about the preferred frequency for the same teaching method. For example, an English version of one item is "Teacher solves problems or sums on blackboard or transparency," answered on a 5-point scale about how much they experienced its use, and also on a 5-point scale about the student's desire for it.

\section{Instrument factor analyses}

Our factor analysis included an exploratory factor analysis (EFA) to identify possible factors, a content analysis to determine appropriate names and definitions for the

Table 1 Item texts for 8 questions on students' attitude

\begin{tabular}{ll}
\hline Item No. & Item Text \\
\hline A1 & Physics and chemistry are difficulty school subjects. \\
A2 & Physics and chemistry are interesting. \\
A3 & Physics and chemistry are easy for me to learn. \\
A4 & What we learned in physics and chemistry lessons are very useful in our daily life. \\
A5 & Physics and chemistry lessons have increased my curiosity about science. \\
A6 & I would like to become a scientist. \\
A7 & I would like to get a job in technology. \\
A8 & Science and technology are important for society. \\
\hline
\end{tabular}


identified factors, then a confirmatory factor analysis (CFA) to extend this by comparing various relationships among the factors.

We began with an exploratory factor analysis (EFA) on the sets of 23 forms of instruction items to identify possible factors for further content analysis. A preliminary analysis indicated 3 factors would best suit the data. Our subsequent content analysis helped us to generate a meaningful factor name and definition for the identified factors. We reviewed each item in all factors and debated the combined meaning of the sets of items in these empirically-derived factors to produce three factor names: cooperative teaching (8 items, e.g., "Students solve problems or complete tasks in small groups." and, "Students conduct experiments in small groups."), constructivist-oriented teaching (7 items, e.g., "Students draw concept maps or other figures/charts." and, "Students hold a debate during the lesson."), and direct teaching (8 items, e.g., "Teacher solves problems or summarizes content on the blackboard." and, "Students learn by reading the textbook."). As the sample items demonstrate, direct teaching consisted of practices that emphasized reception of content knowledge from the teacher, such as having students read from the textbook or describe phenomena and results from experiments, rather than having students plan or conduct experiments for themselves. Cooperative teaching consisted of practices that involved student group work, such as working in groups during class on solving problems or developing small-group projects. Constructivist-oriented teaching consisted of practices that emphasized individual student's building their own knowledge (von Glasersfeld, 2001b) through conceptual development and experiential learning, such as posing and testing one's own questions, drawing and reviewing concept maps, communicating their ideas about science, and engaging in debate about scientific topics.

Our distinction of constructivist-oriented and cooperative teaching practices warrants some clarification. The constructivist stance is built on the tenet that individuals cannot develop knowledge passively but must actively cognize about new experiences in contrast with previous experiences (von Glasersfeld, 2001b). This process is emphatically centered on cognition. In practice, many current efforts to promote constructivistoriented teaching also incorporate a social element. At the minimum, there is a fundamentally social need to provide opportunities for students to verbalize their thinking, by talking to a teacher or to another student, to help stimulate thought and increase reflection on one's thoughts (von Glasersfeld, 1987, 2001a). However, we wished to recognize the possibility that students could be tasked to work in pairs or groups on tasks that are not directly intended to "build knowledge" but that may emphasize transmission of knowledge. For example, students could work in groups to follow a verification-type "cookbook" laboratory, to complete a worksheet, or to review terminology. These examples would provide opportunities for students to cooperate, but would not exhibit the conceptually-rich classroom environments associated with constructivism. This distinction therefore allows use to show the experiences of cooperative activities-without knowing whether they allow for knowledge repetition or knowledge building-from classroom activities more directly associated with constructivist approaches to inquiry and active learning.

Following the content analysis, we conducted CFA to test multiple, competing factor structures that could represent different interpretations of the relationships among the factors. Thus, our CFA process was not just a recapitulation of the EFA findings but 
also allowed more critical tests on the conjectured factor structure-including whether the differentiation of actual and preferred forms of instruction were meaningful. We tested four CFA models with some variations. Model 1 was a unidimensional model that places all items onto a single unidimensional factor. This essentially treats the responses as if there were no sub-factors at all. Model 2 was a first-order model that consisted of a total of 7 factors: one for the Attitude items, and the combinations of Actual vs Preferred responses on the three forms of teaching: Actual-Cooperative, ActualConstructivist, Actual-Direct, Preferred-Cooperative, Preferred-Constructivist, Preferred-Direct. Model 3 was a second-order model, where the Actual and Preferred served as second-order factors to which are attached the Direct, Cooperative, and Constructivist responses. Model 4 was a bifactor model, where each item was loaded onto 2 factors simultaneously: either Actual or Preferred, and either Direct, Cooperative, or Constructivist. For each model, we fit a model variation to determine if a link between the error variance terms for the parallel Actual and Preferred items would improve model fit. The CFA analyses were performed with the lavaan package (Rosseel, 2012) in the R statistical environment (Ihaka \& Gentleman, 1996). We compare the CFA models on several model statistics (Rigdon, 1996); to identify the best fitting model among the candidates. The first, Root Mean Square Error of Approximation (RMSEA), addresses how well the proposed model fits the data; a value is considered acceptable around .08, and is preferred below .05. The second, Comparative Fit Index (CFI), addresses how well a proposed model fits better than a null model; a value is considered acceptable about 0.90 , and preferred to be above .95 . We can also compare models by identifying the model with the lower values on two information criteria statisticsBayesian Information Criterion (BIC) and the corrected Akaike's Information Criterion (AICc) - which allow comparison of different models based on the model's likelihood while controlling for complexity and sample size.

The model statistics are shown in Table 2. The best-fitting model, Model 2, consisted of seven first-order factors: Actual-Cooperative, Actual-Constructivist, Actual-Direct, Preferred-Cooperative, Preferred-Constructivist, Preferred-Direct, and Attitude. This model had the lowest value for RMSEA (0.057, 95\% confidence interval .055-.058), highest CFI (.877), and had the lowest values for AICc (159519) and BIC (160265). We then computed Cronbach's alpha for each of these seven factors, as reported in the last column of Table 3. The high alpha values for the forms of instruction, ranging from .84 for Actual-Direct to .90 for Preferred-Constructivist. The alpha value for Attitude was slightly lower, .77, but still in the acceptable range. Based on the CFA and the good

Table 2 Model fit statistics for the confirmatory factor analysis (CFA) models ( $N=1299)$

\begin{tabular}{lllllllll}
\hline Model & $\mathrm{k}$ & $\mathrm{CFI}$ & RMSEA (C.I.) & SRMR & $\mathrm{X}^{2}$ & $\mathrm{df}$ & AICC & BIC \\
\hline Model 1b: Unidimensional & 131 & .574 & $.105(.103, .106)$ & .103 & $20,603.86$ & 1354 & 173,159 & 173,807 \\
Model 2b: First-Order Factors & 152 & .877 & $.057(.055, .058)$ & .079 & 6911.20 & 1333 & 159,519 & 160,265 \\
Model 3b: Second-Order Factors & 140 & .857 & $.061(.060, .062)$ & .091 & 7807.02 & 1345 & 160,385 & 161,074 \\
Model 4: bifactor unlinked & 169 & .752 & $.081(.080, .082)$ & .049 & $12,538.34$ & 1316 & 165,191 & 166,014 \\
\hline
\end{tabular}

"Linked" versions of models 1-3 have the same structure but include error covariance terms for the parallel Actual and Preferred items linked. k: number of parameters estimated

Abbreviations: CFI Comparative fit index, RMSEA (CI) Root mean square error of approximation with $95 \%$ confidence interval in parentheses, SRMR Standardized root mean-square residual, AICC Corrected Akaike's information criterion, BIC Bayesian information criterion 
Table 3 Descriptive statistics for scales in the study $(N=1299)$

\begin{tabular}{|c|c|c|c|c|c|c|c|}
\hline \multirow[t]{2}{*}{ Variable } & \multicolumn{3}{|l|}{ School Type } & \multicolumn{2}{|l|}{ Gender } & \multicolumn{2}{|l|}{ Overall } \\
\hline & $A$ & $\mathrm{~B}$ & C & Female & Male & & $a$ \\
\hline N & 393 & 573 & 333 & 647 & 652 & 1299 & - \\
\hline Attitude & $2.98(.30)$ & $3.03(.30)$ & $3.10(.32)$ & $2.95(.30)$ & $3.12(.30)$ & $3.03(.31)$ & .76 \\
\hline \multicolumn{8}{|l|}{ Actual } \\
\hline Cooperative & $3.00(.48)$ & $3.08(.44)$ & $3.17(.54)$ & $3.05(.45)$ & $3.11(.52)$ & $3.08(.48)$ & .87 \\
\hline Constructivist-oriented & $2.27(.68)$ & $2.40(.71)$ & $2.82(.97)$ & $2.40(.73)$ & $2.54(.87)$ & $2.47(.81)$ & .88 \\
\hline Direct & $3.88(.52)$ & $3.96(.41)$ & $3.91(.55)$ & $3.94(.44)$ & $3.90(.53)$ & $3.92(.49)$ & .84 \\
\hline \multicolumn{8}{|l|}{ Preferred } \\
\hline Cooperative & $3.68(.55)$ & $3.80(.45)$ & $3.90(.51)$ & $3.78(.44)$ & $3.80(.55)$ & $3.79(.50)$ & .88 \\
\hline Constructivist-oriented & $3.14(.90)$ & $3.39(.81)$ & $3.70(.73)$ & $3.35(.79)$ & $3.44(.89)$ & $3.39(.85)$ & .90 \\
\hline Direct & $4.07(.50)$ & $4.14(.37)$ & $4.15(.51)$ & $4.14(.40)$ & $4.11(.50)$ & $4.12(.45)$ & .86 \\
\hline \multicolumn{8}{|l|}{ Discrepancy } \\
\hline Cooperative & $-0.68(.44)$ & $-0.71(.39)$ & $-0.73(.46)$ & $-0.72(.40)$ & $-0.69(.45)$ & $-0.71(.42)$ & - \\
\hline Constructivist-oriented & $-0.87(.87)$ & $-0.99(.82)$ & $-0.89(.87)$ & $-0.95(.80)$ & $-0.90(.89)$ & $-0.92(.85)$ & - \\
\hline Direct & $-0.19(.27)$ & $-0.18(.24)$ & $-0.24(.32)$ & $-0.19(.26)$ & $-0.20(.29)$ & $-0.20(.27)$ & - \\
\hline
\end{tabular}

Values shown as M (SD). Discrepancy is calculated as Actual-Preferred; negative scores indicate actual instruction was less than what students would prefer. $\alpha$ is Cronbach's alpha

alpha values, we computed latent factor estimates for the seven factors to use for the subsequent analyses described below.

\section{Data analyses}

Following the factor analysis to create latent factor estimates, data analysis proceeded in two phases: ANOVA to test for group differences (research questions 1 and 2); and multiple regression to compare influences on attitudes toward science (research question 3). ANOVAs on the factor scores to answer the first three research question about the discrepancy between students' preference for forms of instruction and their actual experience of the forms of instruction, overall, by gender, and by school type. For each form of instruction (cooperative, constructivist-oriented, and direct), we performed a repeated measures ANOVA to compare the actual and preferred value, and to test whether this discrepancy was affected by gender and by school type for that form of instruction. We selected repeated measures ANOVA because it provides a straightforward test of the difference between the two measures, preferred and actual. While repeated measures ANOVA is frequently applied to test effects of time using the same measures, it is also applicable where the same respondents undergo varied treatment conditions in any order, or situations where respondents complete similar but comparable measures (Girden, 1992). In our situation, the students are responding to questions about a common event, the instructional experience, using identical items rating on two comparable scales-actual and preferred.

We then conducted a regression analysis to answer our final research question about the effect of the forms of instruction on students' attitudes toward science. We regressed the scale score on students' attitude toward science onto a block of control variables for gender and school type, then a block of variables for the preference for forms of instruction, and finally on a block of variables for the discrepancy between 
actual and preference for instruction. This allows us to examine the statistical significance of the demographic variables, the preference for instruction, and actual experience of forms of instruction as predictors of attitude toward science. We focus on the standardized regression coefficients because those are comparable regardless of scale.

\section{Results}

Table 3 presents the descriptive statistics for the variables, including the discrepancy between students' preference and their actual experience.

\section{Discrepancies in preferred and actual experience of instruction}

Our first two research questions were addressed using repeated measures ANOVA to determine if there were significant discrepancies between students' preference for forms of instruction and their actual experience of those forms of instruction, and if such discrepancies were related to students' gender or school type. The repeated measures ANOVA results are shown in Tables 4, 5 and 6 for each of the forms of instruction: Cooperative, Constructivist, and Direct. To answer question 1 on the overall discrepancy by form of instruction, we look to the F-value for discrepancy between actual and preferred instruction. There was a significant discrepancy between students' preference for instruction and the actual experience of that instruction overall, with magnitude of the discrepancy highest for cooperative teaching (Table 4: $\mathrm{F}_{1,1293}=3442.362, p=.000$, partial $\eta^{2}=.727$ ), somewhat lower for constructivist-oriented teaching (Table 5: $\mathrm{F}_{1,1293}=1434.103, p=.000$, partial $\eta^{2}=.526$ ), and lowest for direct instruction (Table 6: $\mathrm{F}_{1,1293}=690.153, p=.000$, partial $\eta^{2}=.348$ ). In all cases (see Table 3), the actual experience of instruction that students reported was lower than what they preferred, which is why the mean discrepancy values are negative. Because of the significant discrepancy values, we continued to look at discrepancy for the remaining questions rather than look only at actual experience of instruction.

Question 2 addresses student difference by gender and school type. For student gender, we look at Tables 2 and 3 at the within-subjects interaction effect with gender to consider if students' self-reported gender is associated with a discrepancy between

Table 4 Repeated measures ANOVA results for cooperative teaching ( $N=1299)$

\begin{tabular}{llllll}
\hline Source & MS & df & F & $p$ & Partial $\eta^{2}$ \\
\hline Within-Subjects Effects & & & & & \\
Discrepancy & 308.866 & 1 & 3442.362 & .000 & .727 \\
Discrepancy * Sex & .142 & 1 & 1.584 & .208 & .001 \\
Discrepancy * School Type & .109 & 2 & 1.212 & .298 & .002 \\
Discrepancy * Sex * School Type & .018 & 2 & .198 & .820 & .000 \\
Error (Discrepancy) & .090 & 1293 & & & \\
Between-Subjects Effects & & & & .260 & .001 \\
Sex & .245 & 1 & 1.269 & .000 & .026 \\
School Type & 3.327 & 2 & 17.249 & .305 & .002 \\
Sex * School Type & .290 & 2 & 1.188 & & \\
Error & .193 & 1293 & & & \\
\hline
\end{tabular}

Significance levels for within-subjects effects are unchanged when using Greenhouse-Geisser or Huynh-Feldt corrections 
Table 5 Repeated measures ANOVA results for constructivist teaching $(N=1299)$

\begin{tabular}{llllll}
\hline Source & MS & df & $F$ & $p$ & Partial $\eta^{2}$ \\
\hline Within-Subjects Effects & & & & & \\
Discrepancy & 513.957 & 1 & 1434.103 & 0.000 & 0.526 \\
Discrepancy * Sex & 0.624 & 1 & 1.742 & 0.187 & 0.001 \\
Discrepancy * School Type & 0.972 & 2 & 2.713 & 0.067 & 0.004 \\
Discrepancy * Sex * School Type & 0.191 & 2 & 0.534 & 0.586 & 0.001 \\
Error (Discrepancy) & 0.358 & 1293 & & & \\
Between-Subjects Effects & & & & & 0.005 \\
Sex & 2.706 & 1 & 5.918 & 0.015 & 0.087 \\
School Type & 28.293 & 2 & 61.866 & 0.000 & 0.001 \\
Sex * School Type & 0.211 & 2 & 0.462 & 0.630 & \\
Error & 0.457 & 1293 & & & \\
\hline
\end{tabular}

Significance levels for within-subjects effects are unchanged when using Greenhouse-Geisser or Huynh-Feldt corrections

actual and preferred instruction. Across all three forms of instruction, we see there were no significant interaction effects of gender with the discrepancy. This means that both boys and girls reported similar discrepancies between the preference for instruction and the actual experience of instruction. We do see, however, a very small but significant between-subject effect for gender regarding the Constructivist-oriented teaching (Table 5: $\mathrm{F}_{1,1293}=5.918, p=.015$, partial $\eta^{2}=.005$ ) - which indicates that boys and girls had an across-the-board difference in their responses on Constructivistoriented teaching. A post hoc t-test revealed that this was because girls reported very slightly lower level of actual Constructivist-oriented teaching in their classes $(p=.002)$ but with a very small effect size $(\mathrm{d}=.17)$. This indicates that girls report a slightly different experience in the classroom environment than the boys do.

To address differences by school type, we look at Table 4, 5 and 6 at the withinsubjects interaction with school type to determine if there is a difference among students of school type on the discrepancy between their actual and preferred forms of instruction. We see that there are non-significant interactions for Cooperative and Constructivist-oriented teaching, indicating that the discrepancy between preference

Table 6 Repeated measures ANOVA results for direct teaching ( $N=1299)$

\begin{tabular}{llllll}
\hline Source & MS & df & F & $p$ & Partial $\eta^{2}$ \\
\hline Within-Subjects Effects & & & & & \\
Discrepancy & 25.663 & 1 & 690.153 & 0.000 & 0.348 \\
Discrepancy * Sex & 0.016 & 1 & 0.432 & 0.511 & 0.000 \\
Discrepancy * School Type & 0.197 & 2 & 5.299 & 0.005 & 0.008 \\
Discrepancy * Sex * School Type & 0.019 & 2 & 0.500 & 0.607 & 0.001 \\
Error (Discrepancy) & 0.037 & 1293 & & & \\
Between-Subjects Effects & & & & & 0.002 \\
Sex & 0.544 & 1 & 2.697 & 0.101 & 0.005 \\
School Type & 0.712 & 2 & 3.529 & 0.030 & 0.001 \\
Sex * School Type & 0.110 & 2 & 0.545 & 0.580 & \\
Error & 0.202 & 1293 & & & \\
\hline
\end{tabular}

Significance levels for within-subjects effects are unchanged when using Greenhouse-Geisser or Huynh-Feldt corrections 
Table 7 Multiple regression analysis for attitude toward science $(N=1299)$

\begin{tabular}{|c|c|c|c|c|}
\hline Coefficient & B & s.e. & $\beta$ & $p$ \\
\hline \multicolumn{5}{|l|}{ Block 1: Control Variables } \\
\hline Intercept & 2.548 & 0.071 & & 0.000 \\
\hline Female & -0.141 & 0.015 & -0.230 & 0.000 \\
\hline SchoolA & -0.061 & 0.021 & -0.092 & 0.003 \\
\hline SchoolB & -0.036 & 0.019 & -0.057 & 0.064 \\
\hline \multicolumn{5}{|l|}{ Block 2: Preferred Instruction } \\
\hline Preferred-Cooperative & 0.285 & 0.042 & 0.465 & 0.000 \\
\hline Preferred-Constructivist & 0.004 & 0.018 & 0.010 & 0.838 \\
\hline Preferred-Direct & -0.067 & 0.033 & -0.099 & 0.042 \\
\hline \multicolumn{5}{|l|}{ Block 3: Discrepancy } \\
\hline Discrepancy-Cooperative & 0.394 & 0.038 & 0.542 & 0.000 \\
\hline Discrepancy-Constructivist & -0.034 & 0.015 & -0.094 & 0.022 \\
\hline Discrepancy-Direct & -0.115 & 0.043 & -0.103 & 0.007 \\
\hline
\end{tabular}

and actual experience was consistent across school types. The exception was for Direct teaching where a significant interaction of discrepancy by school type (Table 6: $\mathrm{F}_{1,1293}=5.299, p=.005$, partial $\left.\eta^{2}=.008\right)$ indicated a small but significant effect. Looking at the means in Table 3, it is clear this small effect is due to the $\mathrm{C}$ school students having a larger discrepancy between their preference for direct teaching and actual experience than their counterparts in the A and B schools. Furthermore, we see across the board between-subjects effects of school type-indicating that students of different school types had across-the-board difference in their responses on the forms of instruction. Looking at the means in Table 3, we see that this occurs because students in the A schools have lower levels of both preference for instruction and reports of actual experience of instruction, regardless of the form of instruction in question.

\section{Multiple regression analysis}

To answer our third research question on how attitude can be explained by the discrepancy between actual and preferred instruction, we conducted a multiple regression analysis with attitude toward science as the dependent variable. We regressed attitude on blocks of variables, beginning with control variables of gender and school type (block 1), then the preference for the forms of instruction (block 2), and last the discrepancy variables for each form of instruction (block 3). The results are shown in Table 7. The block 1 variables together explained $8.8 \%$ of the variation in attitude, block 2 variables together significantly explained an additional $3.8 \%$ of variation in attitude (change in $R^{2}=0.038, \mathrm{~F}_{31292}=18.462, p=.000$ ), and block 3 variables together significantly explained an additional $12.4 \%$ of variation in attitude (change in $R^{2}=0.124, \mathrm{~F}_{31289}=71.166, p=.000$ ). This shows that the discrepancy between actual and preferred instruction in class explained more variation (12.4\%) than the demographic variables alone $(8.8 \%)$ or the preference alone (3.8\%). This supports our decision to address the role of discrepancy as an influence on students' attitudes toward science. 
Looking at the unstandardized regression weights (B's) allows us to interpret the results on the original attitude scale. For the control variables we can see that female students have significantly lower attitudes than male students $(\mathrm{B}=-.141, p=.000)$, and that the students in type A schools (highest performing) have lower attitudes than students in the type $\mathrm{C}$ schools $(\mathrm{B}=-.061, p=.003)$, and that students in the type $\mathrm{B}$ schools have lower attitudes toward science than the students in type $C$ schools $(B=-.036$, $p=.000$ ). Preference for cooperative teaching was associated with more positive attitudes $(\mathrm{B}=.285, \mathrm{p}=.000)$, whereas preference for Constructivist-oriented teaching was non-significant $(\mathrm{B}=.004, p=.838)$. Preference for direct teaching was small but negatively associated with attitudes $(\mathrm{B}=-.067, p=.042)$, but we interpret this tentatively because the $p$-value would be non-significant if a Bonferroni correction were adopted. Among the discrepancy variables, which are based on the difference between Actual and Preferred, we see a positive value for Cooperative teaching $(\mathrm{B}=.394, p=.000)$ indicating that a more positive discrepancy (that is, when the gap between actual experience and what students would prefer is not as high) is associated with higher attitudes on average. By contrast, the significantly negative value for discrepancy for Direct teaching ( $\mathrm{B}=-.115, p=.007)$ shows that students would have higher attitudes associated with a more negative discrepancy (that is, when there is a larger gap between actual experience and what students would prefer). There is also a very small and moderately significant effect of discrepancy for Constructivist oriented teaching $(B=$ $-.034, p=.022$ ), but we interpret this value with caution because of the small size and because the $p$-value would be non-significant if a Bonferroni correction were adopted.

The standardized regression weights ( $\beta$ 's) allow for comparisons of relative influence of different types of variables. From these, we see that the two largest effects were both associated with Cooperative Teaching: Preference for Cooperative teaching had a standardized regression weight of .465 , and Discrepancy in Cooperative Teaching had a standardized regression weight of .542 . The values show that students who prefer cooperative teaching have higher attitudes on average, and that a more positive discrepancy (that is, when the gap between actual experience and what students would prefer is not as high) is associated with higher attitudes on average. So, according to these results, the largest effects of teaching on students' attitudes toward science would be higher when they experience more cooperative teaching, even if it still is not as high as they might prefer.

\section{Discussion and conclusion}

With students' attitudes toward science identified as a valuable outcome of science education, an important line of research is the different ways in which science teaching can help bolster this affective outcome. As this study shows, students' attitudes toward science can be positively related to how their experiences of instruction align with their preferences for instruction, especially for cooperative teaching approaches such as group work in class or developing small-group projects. This suggests that teachers' day-to-day instruction could contribute to positive attitudes toward science by incorporating such cooperative learning strategies ( $\mathrm{Du} \& \mathrm{Gao}, 2010)$. In our sample, this would mean increasing attitude toward science by reducing the gap between students' preference for cooperative teaching and their actual experience of classroom instruction. This is consistent with current efforts to promote more cooperative and inquiry- 
oriented instruction in Chinese contexts (Liang, 2017) that has been encouraged by curriculum leaders (MOE, 2011), while also highlighting that the implementation of more student-centered instruction could remain relatively less prevalent than desired (Huang et al., 2016).

Our findings are also generally consistent with the expectancy-value theory (Eccles \& Wigfield, 2002; Wigfield \& Eccles, 2000), in that students who experienced more cooperative instructional practices-which may heighten their sense of social and personal value-showed more positive attitudes toward school science. This also suggests that, in general, instruction that provides more social engagement for students may increase their attitudes toward the class. The potential for positive effects of cooperative instruction may be particularly high in classroom settings that are otherwise teachercentered, which could be substantially prevalent in Chinese settings like this (Huang et al., 2016). As the students may be experiencing quite low levels of peer-peer interaction around content, the novelty of more cooperative work may be strongly influential on attitude. This conjecture cannot be tested more explicitly in the present data, so further study on this general question is warranted.

There were non-significant effects of constructivist-oriented instruction and small negative effects of direct instruction on students' attitudes. So, while prior work emphasized the value of constructivist-oriented instruction over direction instruction for students' cognitive development and development of richer knowledge and understanding (Fulmer \& Liang, 2013) and suggested that it would improve attitudes in Western settings (Osborne et al., 2003), here we do not see that positive effect of constructivist teaching on students' attitudes. This finding appears to contradict our interpretation of the expectancy-value theory for this context: students did not show more positive attitudes when they have greater epistemic authority (from constructing the knowledge themselves), nor was there a negative effect of being passive in receiving knowledge.

We can see two possible causes for the lack of a positive effect of constructivistoriented teaching that arise because of this sample and how it differed from Western settings where previous work occurred. First, there is the social context of the Chinese classroom setting in which, like much of East Asia, students would expect more traditional teacher-centered instruction (Huang et al., 2016; Tan, 2012) and may not expect to experience constructivist-oriented teaching. So, the lack of constructivist-oriented teaching may be unrelated to their sense of satisfaction with the class or how this is transferred to the discipline itself because they have little overarching reason to expect it. Second, and as a corollary of the first point, there is the possibility of a statistical artifact in the data due to the observed low incidence of constructivist-oriented teaching reported by the students. That is, the students' reports of their actual constructivist-oriented instruction were quite low and-while this finding is somewhat consistent with previous work in such contexts (Yip, 2001) - this means statistically that there was very little variation among the students on this variable. This would constrain the possible correlations with attitude towards science and, thus, affect the regression result. At this time, we are unable to disentangle these two possibilities in the present data set, so further study is warranted that can take into account the special contextual influences in Chinese classrooms that may yield findings that conflict with work in Western settings. It is possible that Chinese teachers in these samples practice so little constructivist-oriented teaching that there is no practical evidence that their students 
develop greater epistemic authority, so that there would not be a contribution of such practices to their attitudes. This is consistent with previous findings about extent of teacher-directed instruction in China (Huang et al., 2016), and exhibits what teachers in the context believe about students being "empty vessels to be filled" (Yip, 2001, p. 758). Because of this constraint, future research is needed to extend this work in contexts where constructivist-oriented teaching is more prevalent, to see if there were a relationship with attitudes when students either could expect to or would be more likely to report experiencing such forms of teaching.

One of the more interesting findings of the study was that the positive effect of discrepancy in cooperative teaching on students' attitudes in the regression findings. Because students always reported a greater preference for forms of teaching than they experienced, the positive effect of discrepancy implies that students' attitudes could have been higher if there were a smaller gap. That is, assuming the observed relationship held, students could have reported more positive attitudes if they experienced more cooperative teaching. This effect was significant even after controlling for gender differences or differences in academic rigor of the schools.

Our study also showed that there were overall effects on attitude for the control variables of gender and school type. For gender, male students had more positive attitudes, which was consistent with previous study such as by Du and Gao (2010) and Wu and Guo (2019). For school type, students in the C schools-which are considered less academically successful-had more positive attitudes This difference in attitude was despite the fact that students in the A and B schools would typically be considered better performing in science. This could be related to the higher academic pressure that students in A and B schools may experience, and the more challenging coursework and assessments in their science classes, which may negatively affect their attitudes.

The current study is among the first to examine the relationships between mainland Chinese students' attitudes toward science and classroom instruction from the students' perspective, which has been identified as a promising direction for study (Fulmer \& Liang, 2013; Marsh, 1984). Additionally, the study considered both the role of students' actual experience of instruction and their stated preference for forms of instruction. Our use of student responses could also explain the possible contradictions with previous work, because we get a measure of what classroom teaching practices the students recognize their teachers using, rather than based on observational data, teacher reports, or group assignment. So, students may find some of the practices less salient in their recollection, and therefore report a lower level of some practices than what a teacher may report doing, or what the teacher may do when being observed, and so on. We see large potential for this work because, in a sense, the student report data give a snapshot of the "experience curriculum" that may differ markedly not only from the intended curriculum (as conveyed in instructional materials) but also from the enacted curriculum (as teachers may view it). To better understand this possibility, future research is needed that can combine student report data with other forms of evidence. One possible direction for study could be to explore in greater depth the ways that cooperative teaching strategies influence attitudes using mixed methods, including not only questionnaires such as that by Juuti et al. (2010) but also with classroom observation and teacher or student interviews. 


\section{Implications for practice and research}

The findings of the study have important implications, in general, and for Chinese science educators and policymakers, in particular. In Chinese culture, a teacher's primary role has been perceived as a "knowledge dispenser" - to transmit knowledge and answer students' questions (Liang, 2017). Consequently, teacher-centered "direct teaching" mode has always been the dominant instructional approach implemented in most Chinese classrooms, which is also one of the approaches preferred by students. In a research article published in Science in 2009, Bao and his colleagues compared Chinese high school graduates with their US counterparts in two domains: understanding of physics concepts, and scientific reasoning. It was found that the Chinese students' performance on the concept/content tests were far better than that of their US counterparts. However, no difference was found between the two groups of students on the scientific reasoning scale. This finding suggests that the traditional content-rich direct teaching could be effective in improving student concept test scores but not in the development of students' scientific reasoning abilities. Given that the modern Chinese science curriculum standards emphasize development of knowledge, scientific processes, and attitudes (e.g., MOE, 2011), direct instruction alone would not be enough to achieve the goals of Chinese science education. The significant influence of cooperative teaching strategies on students' attitude towards science appears to be a promising notion. This suggests that such teaching approaches may support the development of more positive attitudes toward the subject itself, above and beyond any effect on the students' understanding of the subject matter. This finding is tentative, however, as we do not have experimental evidence to give causal link between cooperative teaching and attitudes toward science.

At a more fundamental level, the present work reiterates the value of examining students' perspectives when considering their experience of and preference for science teaching. We see not only that students' perceptions of instruction can relate to cognitive outcomes such as understanding of scientific concepts (Fulmer \& Liang, 2013), but also to affective outcomes such as attitude towards science. As we described above, because constructivist-oriented teaching was quite low in the sample, one direction for future research is to examine the relationships between forms of instruction and student attitudes in contexts where constructivist-oriented teaching is more prevalent. At the same time, further research is also needed to test whether the relationship between cooperative teaching and attitudes toward science is a causal one, to answer the question: If teachers do implement more cooperative strategies, would this yield an increase in attitudes toward science?

Another direction for possible follow-up study is to examine more complex relationships among the measures of instruction based on students' classroom experience, their learning outcomes, and affective measures. For instance, the work of Singh et al. (2002) examined the role of attitude towards science in students' achievement, mediated by time spent studying. Similarly, the inclusion of classroom experiences of instruction may significantly contribute to understanding how attitudes are related to other outcomes like achievement or course enrollment. This may occur directly, but also indirectly through time on task in or out of school, or engagement during class.

We also see avenues for future study to explore different profiles or patterns of students' experiences of instruction, and any connections this may have with their learning 
outcomes. For example, individual students may vary in their reports of the experienced instruction. Such variation in student ratings within classes, if substantial, may be related to other meaningful antecedents (such as student background variables, prior academic performance, achievement orientation) or to outcomes (such as performance, engagement in class, attitude toward science). This could be a very fruitful direction for study.

In sum, the present findings indicate that there are meaningful ways to examine how students experience their teachers' science instruction, and these experiences are related to the students' attitudes toward science. The positive correlation between cooperative teaching and attitude has potential implications for teaching practice. In addition, the findings point to the importance of incorporating students' reports of classroom experience in the study of individual and classroom outcomes and processes.

\section{Acknowledgements}

The authors wish to thank the students for participating in the research. The authors thank the anonymous reviewers for feedback on earlier versions of this manuscript. The authors wish to acknowledge the support of Ms. Chenchen Ding, doctoral student in science education at the University of lowa, for assistance with the Chinese language summary.

\section{Authors' contributions}

All authors contributed to the written manuscript. HM created the initial project, designed the study, gathered the data, and contributed to writing all sections. LLL helped with translation, data analysis, and writing all sections. GWF conducted the statistical analyses and led the manuscript preparation for the group. All authors read and approved the final manuscript.

\section{Authors' information \\ Gavin Fulmer is an Assistant Professor of Science Education at the University of lowa. His research addresses the development and implications of assessment in science education, with a focus on Rasch measurement models and applied quantitative research methods. \\ Hongjia Ma retired as a Professor of Chemistry Teaching and Learning at Nanjing Normal University. Her research addresses secondary chemistry curriculum and pedagogy. She is Secretary-General of the Chemistry Teaching Research Society of Jiangsu Province and Chief Editor, Chemistry Teaching and Learning, Monthly (Published by Nanjing Normal University). \\ Ling Liang is an Associate Professor of science education at La Salle University in Philadelphia. She holds a Ph.D. in Science Education (Physics) from Indiana University at Bloomington, IN USA. She has been engaged in science teaching and research since 1996 and is currently teaching integrated sciences and education courses for preservice teachers at undergraduate and graduate levels.}

Funding

There is no funding to report.

\section{Availability of data and materials}

Data can be made available upon request.

\section{Competing interests}

The authors declare that they have no competing interests.

\section{Author details}

${ }^{1}$ University of lowa, N289 Lindquist Center, lowa City, IA 52242, USA. ${ }^{2}$ Nanjing Normal University, Nanjing, China. ${ }^{3}$ La Salle University, Philadelphia, USA.

Received: 25 July 2019 Accepted: 5 November 2019

Published online: 27 November 2019

\section{References}

Aschbacher, P. R., Li, E., \& Roth, E. J. (2010). Is science me? High school students' identities, participation and aspirations in science, engineering, and medicine. Journal of Research in Science Teaching, 47(5), 564-582. https://doi.org/10.1002/tea. 20353.

Basl, J. (2011). Effect of school on interest in natural sciences: A comparison of the Czech Republic, Germany, Finland, and Norway based on PISA 2006. International Journal of Science Education, 33(1), 145-157. https://doi.org/10.1080/09500693. 2010.518641.

Baviskar, S. N., Hartle, R. T., \& Whitney, T. (2009). Essential criteria to characterize constructivist teaching: Derived from a review of the literature and applied to five constructivist-teaching method articles. International Journal of Science Education, 31, 541-550. https://doi.org/10.1080/09500690701731121.

Bybee, R., \& McCrae, B. (2011). Scientific literacy and student attitudes: Perspectives from PISA 2006 science. International Journal of Science Education, 33(1), 7-26. https://doi.org/10.1080/09500693.2010.518644. 
Clark, R., Kirschner, P. A., \& Sweller, J. (2012). Putting students on the path to learning: The case for fully guided instruction. American Educator, 36(1), 6-11.

Cobern, W. W., Schuster, D., Adams, B., Applegate, B., Skjold, B., Undreiu, A., \& Gobert, J. D. (2010). Experimental comparison of inquiry and direct instruction in science. Research in Science \& Technological Education, 28(1), 81-96.

Dean, D., \& Kuhn, D. (2007). Direct instruction vs. discovery: The long view. Science Education, 91 (3), 384-397.

Driver, R., Asoko, H., Leach, J., Mortimer, E., \& Scott, P. (1994). Constructing scientific knowledge in the classroom. Educational Researcher, 23(7), 5-12.

Du, X., \& Gao, Y. (2010). The characteristics of attitudes toward science of primary and secondary school students. Curriculum, Teaching Material, and Method, 30(9), 87-91.

Durik, A. M., Shechter, O. G., Noh, M., Rozek, C. S., \& Harackiewicz, J. M. (2015). What if I can't? Success expectancies moderate the effects of utility value information on situational interest and performance. Motivation and Emotion, 39(1), 104-118.

Eccles, J. S., \& Wigfield, A. (2002). Motivational beliefs, values, and goals. Annual Review of Psychology, 53, 109-132.

Fulmer, G. W. (2014). Undergraduates' attitudes toward science and their epistemological beliefs: Positive effects of certainty and authority beliefs. Journal of Science Education and Technology, 23(1), 198-206. https:/doi.org/10.1007/s10956-013-9463-7.

Fulmer, G. W., \& Liang, L. L. (2013). Measuring model-based high school science instruction: Development and application of a student survey. Journal of Science Education and Technology, 21(1), 37-46. https://doi.org/10.1007/s10956-011-9287-2.

Furtak, E. M., Seidel, T., Iverson, H., \& Briggs, D. C. (2012). Experimental and quasi-experimental studies of inquiry-based science teaching: A meta-analysis. Review of Educational Research, 82(3), 300-329.

Gao, L., \& Watkins, D. A. (2002). Conceptions of teaching held by school science teachers in PR China: Identification and cross-cultural comparisons. International Journal of Science Education, 24(1), 61-79.

George, R. (2000). Measuring change in students' attitudes toward science over time: An application of latent variable growth modeling. Journal of Science Education \& Technology, 9(3), 213-225.

Gibson, H. L., \& Chase, C. (2002). Longitudinal impact of an inquiry-based science program on middle school students' attitudes toward science. Science Education, 86(5), 693-705.

Gillies, R. M. (2003). Structuring cooperative group work in classrooms. International Journal of Educational Research, 39, 35-49.

Girden, E. R. (1992). Quantitative applications in the social sciences: ANOVA. Thousand Oaks: SAGE Publications, Inc.. https://doi. org/10.4135/9781412983419.

Hand, B., Cavagnetto, A., Chen, Y. C., \& Park, S. (2016). Moving past curricula and strategies: Language and the development of adaptive pedagogy for immersive learning environments. Research in Science Education, 46(2), 223-241.

Hänze, M., \& Berger, R. (2007). Cooperative learning, motivational effects, and student characteristics: An experimental study comparing cooperative learning and direct instruction in 12th grade physics classes. Learning and Instruction, 17(1), 2941. https://doi.org/10.1016/j.learninstruc.2006.11.004.

Hazari, Z., Tai, R. H., \& Sadler, P. M. (2007). Gender differences in introductory university physics performance: The influence of high school physics preparation and affective factors. Science Education, 91(6), 847-876.

Hollingsworth, J. R., \& Ybarra, S. E. (2017). Explicit direct instruction (EDI): The power of the well-crafted, well-taught lesson (2nd ed.). Thousand Oaks: Corwin Press.

Hong, Z.-R., \& Lin, H.-S. (2011). An investigation of students' personality traits and attitudes toward science. International Journal of Science Education, 33(7), 1001-1028. https://doi.org/10.1080/09500693.2010.524949.

Houseal, A. K, Abd-El-Khalick, F., \& Destefano, L. (2014). Impact of a student-teacher-scientist partnership on students' and teachers' content knowledge, attitudes toward science, and pedagogical practices. Journal of Research in Science Teaching, 51, 84-115.

Huang, X., Ding, L., \& Hu, B. (2016). Science curriculum and implementation in senior secondary school. In L. L. Liang, X. X. Liu, \& G. W. Fulmer (Eds.), Chinese Science Education in the 21st century: Policy, practice, and research. Dordrecht: Springer.

Ihaka, R., \& Gentleman, R. (1996). R: a language for data analysis and graphics. Journal of computational and graphical statistics, 5(3), 299-314.

Juuti, K., Lavonen, J., Uitto, A., Byman, R., \& Meisalo, V. (2010). Science teaching methods preferred by grade 9 students in Finland. International Journal of Science and Mathematics Education, 8(4), 611-632.

Kame'enui, E. J., Jitendra, A. K., \& Darch, C. B. (1995). Direct instruction reading as contronym and eonomine. Reading \& Writing Quarterly, 11, 3-17. https://doi.org/10.1080/1057356950110102.

Kanter, D. E., \& Konstantopoulos, S. (2010). The impact of a project-based science curriculum on minority student achievement, attitudes, and careers: The effects of teacher content and pedagogical content knowledge and inquirybased practices. Science Education, 94, 855-887.

Kennedy, K. J. (2007). Barriers to innovative school practice: A socio-cultural framework for understanding assessment practices in Asia. In Paper presented at the redesigning pedagogy-culture, understanding and practice conference, Singapore.

Kirschner, P. A., Sweller, J., \& Clark, R. E. (2006). Why minimal guidance during instruction does not work: An analysis of the failure of constructivist, discovery, problem-based, experiential, and inquiry-based teaching. Educational Psychologist, 41, 75-86. https://doi.org/10.1207/s15326985ep4102_1.

Koballa, T. R., \& Glynn, S. M. (2007). Attitudinal and motivational constructs in science learning. In S. K. Abell \& N. G. Lederman (Eds.), Handbook of research on science education. Mahwah: Lawrence Erlbaum.

Koksal, E. A., \& Berberoglu, G. (2014). The effect of guided-inquiry instruction on 6th grade Turkish students' achievement, science process skills, and attitudes toward science. International Journal of Science Education, 36, 66-78.

Liang, L. L. (2017). Editor's introduction: Science curriculum and instruction. In L. L. Liang, X. Liu, \& G. W. Fulmer (Eds.), Chinese science education in the $21^{\text {st }}$ century: Policy, practice, and research. Netherlands: Springer.

Liang, L. L., Fulmer, G. W., Majerich, D. M., Clevenstine, R., \& Howanski, R. (2012). The effects of a model-based physics curriculum program with a physics first approach: A causal-comparative study. Journal of Science Education and Technology, 21(1), 114-124.

Loyens, S. M. M., \& Rikers, R. M. J. P. (2016). Instruction based on inquiry. In R. E. Mayer \& P. A. Alexander (Eds.), Handbook of research on learning and instruction (pp. 361-381). New York: Routledge.

Maltese, A. V., \& Tai, R. H. (2010). Eyeballs in the fridge: Sources of early interest in science. International Journal of Science Education, 32(5), 669-685. https://doi.org/10.1080/09500690902792385.

Marsh, H. W. (1984). Students' evaluations of university teaching: Dimensionality, reliability, validity, potential biases, and utility. Journal of Educational Psychology, 76(5), 707-754. 
Ministry of Education (MOE). (2011). National physics curriculum standards for the full-time compulsory education (Grades 7-9). [义务教育物理课程标准]. Beijing: Beijing Normal University Press (in Chinese).

Minstrell, J., \& Kraus, P. (2005). Guided inquiry in the science classroom. In S. Donovan \& J. D. Bransford (Eds.), How students learn: History, mathematics, and science in the classroom (pp. 475-513). Washington, D.C.: National Academy Press.

Newell, A. D., Zientek, L. R., Tharp, B. Z., Vogt, G. L., \& Moreno, N. P. (2015). Students' attitudes toward science as predictors of gains on student content knowledge: Benefits of an after-school program. School Science and Mathematics, 115(5), 216225. https://doi.org/10.1111/ssm.12125.

Osborne, J., Simon, S., \& Collins, S. (2003). Attitudes towards science: A review of the literature and its implications. International Journal of Science Education, 25(9), 1049. https://doi.org/10.1080/0950069032000032199.

Peer, J., \& Fraser, B. J. (2015). Sex, grade-level and stream differences in learning environment and attitudes to science in Singapore primary schools. Learning Environments Research, 18(1), 143-161.

Potvin, P., \& Hasni, A. (2014). Interest, motivation and attitude towards science and technology at K-12 levels: A systematic review of 12 years of educational research. Studies in Science Education, 50(1), 85-129.

Raved, L., \& Assaraf, O. B. Z. (2011). Attitudes towards science learning among 10th-grade students: A qualitative look. International Journal of Science Education, 33(9), 1219-1243. https://doi.org/10.1080/09500693.2010.508503.

Rice, L., Barth, J. M., Guadagno, R. E., Smith, G. P., \& McCallum, D. M. (2013). The role of social support in students' perceived abilities and attitudes toward math and science. Journal of Youth and Adolescence, 42(7), 1028-1040.

Rigdon, E. E. (1996). CFI versus RMSEA: A comparison of two fit indexes for structural equation modeling. Structural Equation Modeling: A Multidisciplinary Journal, 3(4), 369-379.

Rosseel, Y. (2012). Lavaan: An R package for structural equation modeling and more. Version 0.5-12 (BETA). Journal of statistical software, 48(2), 1-36.

Sadler, P. M., Sonnert, G., Hazari, Z., \& Tai, R. (2012). Stability and volatility of STEM career interest in high school: A gender study. Science Education, 96(3), 411-427.

Schreiner, C., \& Sjøberg, S. (2004). Sowing the seeds of ROSE: Background, rationale, questionnaire development and data collection for ROSE (the relevance of science education) - A comparative study of students' views of science and science education. Oslo: Department of Teacher Education and School Development, University of Oslo.

Singh, K., Chang, M., \& Dika, S. (2005). Affective and motivational factors in engagement and achievement in science. International Journal of Learning, 12(6), 207-218.

Singh, K., Granville, M., \& Dika, S. (2002). Mathematics and science achievement: Effects of motivation, interest, and academic engagement. Journal of Educational Research, 95(6), 323.

Sjøberg, S., \& Schreiner, C. (2010). The ROSE project. An overview and key findings. Norway: University of Oslo Retrieved from https://roseproject.no/network/countries/norway/eng/nor-Sjoberg-Schreiner-overview-2010.pdf.

Slavin, R. E. (2016). Instruction based on cooperative learning. In R. E. Mayer \& P. A. Alexander (Eds.), Handbook of research on learning and instruction (pp. 344-360). New York: Routledge.

Taconis, R., \& Kessels, U. (2009). How choosing science depends on students' individual fit to 'Science culture'. International Journal of Science Education, 31(8), 1115-1132. https://doi.org/10.1080/09500690802050876.

Tan, C. (2012). The culture of education policy making: Curriculum reform in Shanghai. Critical Studies in Education, 53(2), 153167. https://doi.org/10.1080/17508487.2012.672333.

Tytler, R., \& Osborne, J. (2012). Student attitudes and aspirations towards science. In B. J. Fraser \& C. J. McRobbie (Eds.), Second international handbook of science education (pp. 597-625). Dordrecht: Springer.

Urdan, T., \& Schoenfelder, E. (2006). Classroom effects on student motivation: Goal structures, social relationships, and competence beliefs. Journal of School Psychology, 44, 331-349.

Vedder-Weiss, D., \& Fortus, D. (2012). Adolescents' declining motivation to learn science: A follow-up study. Journal of Research in Science Teaching, 49(9), 1057-1095. https://doi.org/10.1002/tea.21049.

von Glasersfeld, E. (1987). Constructivism. In T. Husen \& T. N. Postlethwaite (Eds.), The international encyclopedia of education. Oxford: Pergamon Press.

von Glasersfeld, E. (2001a). Radical constructivism and teaching. Prospects, 31(2), 161-173.

von Glasersfeld, E. (2001b). The radical constructivist view of science. Foundations of Science, 6, 31-43.

Wang, M. T., \& Degol, J. (2013). Motivational pathways to STEM career choices: Using expectancy-value perspective to understand individual and gender differences in STEM fields. Developmental Review, 33(4), 304-340.

Wang, M. T., \& Eccles, J. S. (2012). Social support matters: Longitudinal effects of social support on three dimensions of school engagement from middle to high school. Child Development, 83, 877-895.

Wang, T.-L., \& Berlin, D. (2010). Construction and validation of an instrument to measure Taiwanese elementary students' attitudes toward their science class. International Journal of Science Education, 32(18), 2413-2428. https://doi.org/10.1080/ 09500690903431561.

Weinburgh, M. (1995). Gender differences in student attitudes toward science: A meta-analysis of the literature from 1970 to 1991. Journal of Research in Science Teaching, 32(4), 387-398. https://doi.org/10.1002/tea.3660320407.

Wigfield, A., \& Eccles, J. S. (2000). Expectancy-value theory of achievement motivation. Contemporary Educational Psychology, 25, 68-81. https://doi.org/10.1006/ceps.1999.1015.

Wu, Y., \& Guo, Y. (2019). Gender difference in science learning and curriculum response: The data analysis of four provinces in China based on PISA 2015. Journal of East China Normal University, Educational Sciences, 5, 115-127. https://doi.org/10. 16382/j.cnki.1000-5560.2019.05.010.

Yip, D. Y. (2001). Promoting the development of a conceptual change model of science instruction in prospective secondary biology teachers. International Journal of Science Education, 23(7), 755-770. https://doi.org/10.1080/09500690010016067.

Zeyer, A. (2017). Gender, complexity, and science for all: Systemizing and its impact on motivation to learn science for different science subjects. Journal of Research in Science Teaching. https://doi.org/10.1002/tea.21413 [online first edition].

\section{Publisher's Note}

Springer Nature remains neutral with regard to jurisdictional claims in published maps and institutional affiliations. 